\title{
UTILIZAÇÃO DO HIDROGEL NA PRODUÇÃO DE MUDAS DE PIMENTA JALAPEÑO
}

\author{
Luis Eduardo Vieira Pinto ${ }^{1}$, Marcio Rogério Santana ${ }^{2}$, Angela Madalena Marchizelli Godinho ${ }^{3}$ \\ 1,2,3 Faculdade de Tecnologia de Pres. Prudente - FATEC. E-mail: coordenacaovrpp@gmail.com
}

\begin{abstract}
RESUMO
A utilização de mudas é a alternativa mais viável para os produtores que procuram maior rendimento e produtividade na sua cultura. Visando aumentar a economia de recursos naturais, 0 presente trabalho foi desenvolvido para fomentar a diminuição do consumo de água na fase de formação de mudas de pimenta Jalapeño (Capsicum annuum), com a utilização do polímero hidroretentor (hidrogel), que possui a capacidade de reter e fornecer água aos poucos para a planta, diminuindo a frequência de irrigação e reduzindo custos de produção. O experimento foi realizado nas estufas da Faculdade de Tecnologia de Presidente Prudente - SP. Utilizou-se o delineamento experimental inteiramente casualizado, composto de 8 tratamentos (doses do polímero) com 15 repetições e 1 planta por unidade experimental. A adição do hidrogel na dose de 8 gramas por litro de substrato resultou no melhor desenvolvimento das mudas de pimenta Jalapeño.
\end{abstract}

Palavras-chave: Polímero Hidroretentor; Água; Capsicum annuum; Substrato.

\section{HYDROGEL OF USE IN JALAPENO PEPPER SEEDLINGS PRODUCTION}

\begin{abstract}
The use of seedlings is the most viable alternative for producers seeking greater efficiency and productivity in their culture. To increase the economy of natural resources, this work was developed to promote the reduction of water consumption at the stage of seedlings Jalapeño pepper (Capsicum annuum), using the hidroretentor polymer (hydrogel), which has the ability to retaining and gradually supply water to the plant, reducing the frequency of irrigation and reducing production costs. The experiment was conducted in the greenhouses of Presidente Prudente Technology School - SP, used the completely randomized design, containing eight treatments (polymer doses), with 15 replications and one plant each. The addition of hydrogel at a dose of 8 grams per liter of substrate resulted in better development of Jalapeno pepper seedlings.
\end{abstract}

Keywords: Polymer Hidroretentor; Water; Capsicum annuum; Substrate. 


\section{INTRODUÇÃO}

A pimenta é uma das especiarias mais utilizadas no mundo, tanto para fins culinários na elaboração de diversos pratos, quanto medicinais; pois há estudos que comprovam a sua eficiência na prevenção de diversos tipos de doenças. Por ser rica em antioxidante e em vitaminas do tipo $\mathrm{A}$ e $\mathrm{C}$ e conter um alto teor de flavonóides, o consumo da pimenta pode reduzir o risco de câncer de próstata, diabetes e cataratas. Ainda, pelo seu efeito termogênico, a ppimenta acelera o metabolismo, auxiliando na perda de peso (LUNN, 2007).

Há relatos dos exploradores espanhóis e portugueses que a pimenta era amplamente cultivada e utilizada pelos índios brasileiros que a empregavam largamente como tempero, para tornar a ingestão de carnes e cereais mais atraente. Era utilizada também como curativo, pois possui ação antisséptica, analgésica, cicatrizante e anti-hemorrágica quando o seu pó é colocado diretamente sobre a pele machucada. Utilizada como como aditivo alimentar, essas civilizações conheciam a contribuição dos frutos da pimenta pelo aroma. Possuía também a função de preservar os alimentos da contaminação por bactérias e fungos patogênicos, contribuindo para a saúde, longevidade e a manutenção da capacidade reprodutiva daquela gente (REIFSCHNEIDER, 2000).

O gênero Capsicum compreende cerca de 30 espécies conhecidas e pertence à família Solanaceae, a mesma da berinjela e da batata. O princípio ativo principal desse gênero é a capsaicina. No Brasil são feitos diferentes usos das pimentas e para cada um existe um tipo de preparo ou procedimento. As pimentas podem ser saboreadas in natura, desidratadas ou em forma de molhos (BONTEMPO, 2007).

A pimenta Jalapeño é a variedade mais conhecida das Américas, pertence à espécie Capsicum annuum e é originária da cidade de Jalapa no México. É utilizada tanto para consumo in natura como processada na forma de pó e molhos. A Jalapeño possui pungência em torno de 30.000 SHU (unidade de calor Scoville), sendo assim, considerada medianamente picante. Caracteriza-se pelos frutos relativamente grandes podendo chegar a medir até $8 \mathrm{~cm}$ de comprimento e $3 \mathrm{~cm}$ de diâmetro, de sabor forte e aromático, sendo comercializada e consumida quando ainda apresenta coloração verde. A sua generosa polpa lhe garante como a melhor variedade para a produção de molhos e conservas. A planta cresce a uma altura de $1 \mathrm{~m}$, com haste robusta, muitas vezes múltipla. As flores, de coloração branca e anteras cinza, são em número de uma por nó. Gosta de clima seco com solo rico em matéria orgânica e bem drenado. No Brasil a área cultivada com Jalapeño ainda é muito pequena, restringe-se aos estados de Minas Gerais, 
Goiás e São Paulo, mas o interesse por esse tipo de pimenta por parte das indústrias de processamento é crescente (RIBEIRO et al., 2002).

A formação de mudas de boa qualidade é a etapa mais importante do sistema produtivo de hortaliças, pois permite melhor planejamento da produção e contribui para a profissionalização dos produtores frente a um mercado cada vez mais competitivo (MINAMI, 1995).

A produção de mudas é influenciada pelo tipo do recipiente e de substrato empregados. primeiro, afeta o volume de substrato disponível para o desenvolvimento das raízes e o segundo, exerce influência na arquitetura do sistema radicular e no estado nutricional das plantas (LATIMER, 1991; SPURR e BARNES, 1982).

Define-se o produto hidrogel como sendo composto por redes poliméricas tridimensionais que podem reter uma quantidade significativa de água dentro de sua própria estrutura e inchar, sem a dissolução (RUI et al., 2007). O polímero hidrorretentor foi criado pelo químico alemão J. Bezelius em 1832. O surgimento do polímero no ponto de vista científico iniciou-se na segunda metade do século passado, porém só veio a ser utilizado como é conhecido hoje após 1922 (HAGE Jr. 2008). Na época, a capacidade de retenção de água deionizada não ultrapassava 20 vezes a sua massa. Com a expiração da patente nos anos 70, uma empresa britânica melhorou as propriedades de retenção de água do polímero, elevando a capacidade de retenção de 20 para 40 vezes e de 40 para 400 vezes no ano de 1982. Porém, a sua utilização na agricultura não foi possível, pela falta de pesquisa específica sobre as recomendações de uso e aplicação do produto para esse fim (AZEVEDO, et al., 2002 apud WOFFORD JR. e KOSKI, 1990).

A partir de 1980, foram desenvolvidos vários trabalhos para a comprovação da eficiência do hidrogel na agricultura, como condicionadores de solo e principalmente para avaliar a sua capacidade de armazenamento de água no solo onde ele é adicionado (WILLINGHAM JR. et al. 1981; WALLACE, 1987). Já no Brasil essas pesquisas com o hidrogel na agricultura aconteceram mais tardiamente com experimentos realizados por Balena (1998 )e Azevedo (2000). A adição de hidrogel no solo otimiza a disponibilidade de água, reduz as perdas por percolação e lixiviação de nutrientes e melhora a aeração e drenagem do solo, acelerando o desenvolvimento do sistema radicular e da parte aérea das plantas (AZEVEDO et al., 2002).

O objetivo deste trabalho foi realizar um estudo para identificar a melhor dose do polímero hidroabsorvente hidrogel HB 20 na produção de mudas de pimenta Jalapeño. 


\section{METODOLOGIA}

O experimento foi realizado na Faculdade de Tecnologia de Presidente Prudente - FATEC, nos meses de novembro e dezembro de 2014 durante a fase de formação de mudas da pimenta Jalapeño. Utilizou-se o delineamento experimental inteiramente casualizado, contendo 8 tratamentos (doses do polímero), com 15 repetições e 1 planta por unidade experimental. As doses do polímero foram distribuídas da seguinte forma:

- Tratamento 01 - substrato sem o hidrogel (Testemunha);

- Tratamento 02 - (1,0 grama de hidrogel por litro de substrato);

- Tratamento 03 - (2,0 gramas de hidrogel por litro de substrato);

- Tratamento 04 - (3,0 gramas de hidrogel por litro de substrato);

- Tratamento 05 - (4,0 gramas de hidrogel por litro de substrato);

- Tratamento 06 - (8,0 gramas de hidrogel por litro de substrato);

- Tratamento 07 - (10,0 gramas de hidrogel por litro de substrato);

- Tratamento 08 - (20,0 gramas de hidrogel por litro de substrato).

Para a realização do experimento foram utilizadas sementes de pimenta Jalapeño retiradas de plantas matrizes, exigindo que a mesma estivesse no seu estado de maturação completo e livre de pragas e doenças.

Após a separação da polpa, as sementes foram reservadas para a secagem a sombra durante quatorze dias. A semeadura foi realizada em bandeja de isopor de 128 células, utilizandose substrato natural à base de fibra de coco da marca Bioplant e o produto hidrogel agrícola (HB 20). Foram semeadas três sementes por célula e assim que as mesmas germinaram foi realizado o desbaste deixando somente uma planta. As mudas receberam irrigação diária de $10 \mathrm{~mm}$ afim de garantir o fornecimento de água para ação do polímero. Trinta dias após a semeadura, as plantas foram coletadas e encaminhadas para a realização das avaliações biométricas em laboratório. Com o auxílio de uma trena foi aferido o comprimento da parte aérea das plantas. Após a lavagem das plantas, as mesmas foram colocadas em sacos de papel Kraft e levadas para a estufa de circulação forçada de ar, por onde permaneceram durante um período de 72 horas mantendose a temperatura na faixa de $65^{\circ}-70^{\circ} \mathrm{C}$. Após a secagem do material, realizou-se um corte na região do colo da planta para seccionar a raiz e parte aérea para posterior pesagem.

Todos os dados foram submetidos à análise de variância (ANOVA, $p<0,05$ ) e ao teste de comparação de médias Scott-Knott $(p<0,05)$, segundo Silva (2011). 


\section{RESULTADOS}

Tabela 1. Resultados das análises estatísticas das variáveis analisadas massa seca da raiz (MSR), massa seca da parte aérea (MSPA) e comprimento da parte aérea (CPA).

\begin{tabular}{cccc}
\hline DOSES DE HIDROGEL $(\mathrm{g})$ & MSR $(\mathrm{g})$ & MSPA $(\mathrm{g})$ & CPA $(\mathrm{cm})$ \\
\hline 0 & $0,142 \mathrm{c}$ & $0,266 \mathrm{~d}$ & $4,533 \mathrm{c}$ \\
1 & $0,179 \mathrm{c}$ & $0,227 \mathrm{~d}$ & $4,000 \mathrm{c}$ \\
2 & $0,211 \mathrm{c}$ & $0,260 \mathrm{~d}$ & $4,800 \mathrm{c}$ \\
4 & $0,277 \mathrm{c}$ & $0,324 \mathrm{c}$ & $5,633 \mathrm{~b}$ \\
6 & $0,277 \mathrm{c}$ & $0,357 \mathrm{c}$ & $5,866 \mathrm{~b}$ \\
8 & $0,478 \mathrm{a}$ & $0,600 \mathrm{a}$ & $7,566 \mathrm{a}$ \\
10 & $0,300 \mathrm{~b}$ & $0,352 \mathrm{c}$ & $6,333 \mathrm{~b}$ \\
20 & $0,468 \mathrm{a}$ & $0,439 \mathrm{~b}$ & $6,933 \mathrm{a}$ \\
\hline MÉDIA GERAL & 0,291 & 0,348 & 5,708 \\
\hline CV (\%) & 34,35 & 27,56 & 18,6 \\
\hline
\end{tabular}

Médias seguidas de mesma letra não diferem estatisticamente pelo teste de Scott-Knott (5\%)

\section{DISCUSSÃO}

Observa-se na Tabela 1 que para a variável massa seca da raiz (MSR) a partir da dose de 8 gramas de polímero por litro de substrato houve um incremento significativo na produção de biomassa, quando comparado com a testemunha e as demais doses utilizadas no experimento. Já para a variável massa seca da parte aérea (MSPA) o incremento ocorreu a partir da dose de 4 gramas de polímero, o mesmo ocorreu para a variável comprimento da parte aérea (CPA). Os resultados estão em concordância com Bearce e McCollum (1993) que realizaram um experimento com crisântemo e lírio e verificaram um maior ganho na massa seca, havendo também um aumento na disponibilidade de água no solo que passou de $39 \%$ para $52 \%$ em valores relativos. Já no cultivo do lírio, além do aumento de massa seca houve também um maior número de brotações, sendo atribuído ao melhor desenvolvimento do sistema radicular.

Nota-se que a dose de 20 gramas por litro de substrato não obteve o mesmo desenvolvimento de massa seca da parte aérea das mudas quando comparado ao tratamento em que foi utilizado 8 gramas por litro de substrato, o que indicou que a maior quantidade de hidrogel não melhorou o desempenho da planta em todos os aspectos, conflitando com a análise de Pill e Stubbolo (1986), que concluíram que a utilização de polímero no substrato, juntamente com uma solução de fertilizantes não afetou significativamente o ganho de peso fresco das raízes de tomateiro e alface. No entanto, houve um maior crescimento de raízes com o aumento da dose de polímero e da solução de fertilizante no substrato. 
Doses muito baixas de hidrogel não refletiram positivamente no maior desenvolvimento das mudas de pimenta Jalapeño. A utilização do hidrogel na dose de 10 gramas por litro de substrato mostrou-se intermediária, pois sempre obteve resultados inferiores às doses de 8 e 20 gramas de hidrogel por litro de substrato. As doses de 8 e 20 gramas de hidrogel promoveram os melhores resultados de incremento de biomassa da raiz e parte aérea das mudas de pimenta, assim como também promoveram o maior crescimento da parte aérea. Porém, a utilização da dose de 8 gramas torna-se mais viável por reduzir o custo de produção das mudas quando comparado com a dose de 20 gramas.

\section{CONCLUSÃO}

A adição do hidrogel na dose de 8 gramas por litro de substrato resultou no melhor desenvolvimento das mudas de pimenta Jalapeño.

\section{REFERENCIAS}

AZEVEDO, T. L.; BERTONHA, A.; GONÇALVES, A. C. A. Uso de hidrogel na agricultura. Revista do programa de Ciência Agro-ambientais, Alta Floresta. V1, n.1, p. 23-31, 2002.

BEARCE, B. C.; MCCOLLUM, R. W. A comparison of peat-lite and noncomposted hardwood-bark mixes for use in pot and bedding-plant production and the effects of a new hydrogel soil amendment on their performance. Virginia, 1993. Disponível em: $<$ http://www.hydrosource.com>.

BONTEMPO, M. Pimenta e seus benefícios à saúde - Marcio Bontempo. São Paulo: Alaúde Editorial, 2007.

HAGE Jr., E. Aspectos Históricos sobre o Desenvolvimento da Ciência e da Tecnologia de Polímeros. 2008. Disponível em: <http://www.scielo.br/scielo.php?script=sci_arttext\&pid=S0104$>$

LATIMER, J.G. Container size and shape influence growth and landscape performance of marigold seedling. HortScience, v.26, n.2, p.124-126, 1991.

LUNN, J. Nutrição e envelhecimento saudável. Nutrição em Pauta. São Paulo, ano 15, v. 85, p. 5-9, jul/ago 2007.

MINAMI, K. Produção de mudas de alta qualidade em horticultura. São Paulo: T.A. Queiroz, 1995. $128 p$.

PILL, W.G.; STUBBOLO, M.R. Tomato seedling growth in peat and peat-lite blocks amended with hydrophilic polymer. Soil Science Plant Anal, v.17, n.1, p.45-61, 1986. http://dx.doi.org/10.1080/00103628609367695 
REIFSCHNEIDER, F.J.B. (Org.). Capsicum: pimentas e pimentões no Brasil. Brasília: Embrapa Comunicação para Transferência de Tecnologia/Embrapa Hortaliças, 2000. 113p

RUI, L.; MINGZHU, L.; LAN, W. Controlled release NPK compound fertilizer with the function of water retention. Reactive and Functional Polymers, v.67, p.769-779, 2007. http://dx.doi.org/10.1016/j.reactfunctpolym.2006.12.007

RIBEIRO, C. S. da C. Lançamento de três cultivares de pimenta do tipo Jalapeño pela Embrapa Hortaliças. 2002. Disponível em: <http//www.abhorticultura.com.br>

SILVA, F. de A. S. Assistat Software - Assistência Estatística. Versão 7.6 beta (2011). Disponível em http://www.assistat.com/indexp.html.

SPURR, S.H.; BARNES, B.V. Ecologia florestal. México: AGT, 1982.

WALLACE, A.; WALLACE G. A.; ABOUZAMZAM, A.M. Amelioration of soil sodic with polymers. Soil Science, Baltimore, v.141, n.5, p.359-362, 1986. http://dx.doi.org/10.1097/00010694-19860500000011

WILLINGHAM, Jr.; COFFEY, D. L. Influence of hydrophilic amended soil on growth of tomato transplants. Hortculture Science, v.16, n.3, p.289, 1981.

WOFFORD Jr., D.J. Worldwide research suggestions for cross-linked polyacrilamide in agriculture (on line). Virginia, September 1992. [cited nov. 1998]. Disponível em: <http://www.hydrosource.com> 